\title{
The Impact of Artificial Intelligence on Innovation
}

\section{Takudzwa Fadziso}

Institute of Lifelong Learning and Development Studies, Chinhoyi University of Technology, ZIMBABWE

*Corresponding Contact:

Email: Fadziso1989@gmail.com

\begin{abstract}
Artificial intelligence has the potential to greatly increase the efficiency of the current life in which we live. However, it may result in more impacts through its application as the modern mode in invention and bring a new perspective of the existing innovation processes in the organization of $R$ \& D. Application of machines' intelligence such as robots from the recent development is a vivid example of invention brought about by the innovation filtered via artificial intelligence. Innovative ways through invention have a sense of replacement in man's duties in the world's varied economic sectors. Large datasets and algorithms will be used in research industries, and the latter will result in potential racing, monitored incentives by large companies, and particular algorithms. However, transparency and transfer of information between public and private will be the engine source to stimulate healthy inventions and innovation programs shortly. Rapid advancement in the artificial intelligence arena has significant sound impacts on society as far as the economy is concerned. Production and characteristics of many products and services have a high potentiality to be directly influenced by these innovations, and important productivity, competition, and employment implications. Even though these innovations will positively influence the largest proportion of human lives, artificial intelligence (A.I.) can potentially change its innovation processes, accompanied by approximately thoughtful consequences, and may gradually dominate the direct consequence.
\end{abstract}

Key Words: Artificial intelligence, innovation, competition policy, economic cost

\section{INTRODUCTION}

Over the past, human races have gone through struggles of making work easier and efficient. However, reliance on natural human intelligence has not proven solutions to the general and complex hick-ups in daily lives. As a result, the need for the most effective ways has been raised to find a breakthrough to achieve the simplest but satisfying ways. For this reason, the use of machine intelligence has taken a route in the human activities that require efficiency. The application of these efficient and effective machines is termed artificial intelligence. The term in human understanding brings varied views about the 
cues and pros and cons. Artificial Intelligence (A.I.) is the intelligence applied to machines, and machines demonstrate its usefulness in the output in terms of first services and high quality of the services and product. A.I. is most precise and accurate, unlike the natural intelligence demonstrated by humans and animals (Happy et al., 2015). A.I. cannot be mentioned without innovation and technology, efficiency, cost-effective, timesaving, and problem-solving. Therefore, this paper aims to demonstrate how A.I. has proven myriad impacts in the real world and innovation in the technological world.

The work accorded to human performance keeps on escalating every second. The simulation of the human process's operationalization has raised the concern to develop A.I. machines that would mimic the human processes, though in a faster way and means. The processes that have been able to be mimicked by machines include reasoning, learning, and self-rectification. Several flaws at the places of work are aimed to be reduced and improve on the quality output. Moreover, human life has found effectiveness and efficiency. Human memory is limited to powering many and numerous programs in their daily lives. In this case, multi-tasking may lead to some omission and flaws in some processes. As a result of omission, the processes' necessity may result in a compromised output of the desired information. Thus, A.I. has taken the crucial role of powering many programs in day-to-day human lives.

Further, social media is the direct benefice of A.I. application in its informative services to all races in the world's families and races. Connecting with families and friends worldwide via e-mail programs and ride-share services is attributed to A.I.'s development's impulsive effect. The application of A.I. in chatbots has promoted accuracy in recognizing similarities in different platforms where customers inquire about similar knowledge. Accessibility to vital information search sources has been put at the palm of human hands. At the press of the button, Google assistance has been allowing most populations to search for anything they require from the web. Tasks schedule and checking such schedule has been made portable across the net across the globe.

The driving force of every activity that has raised the need for efficiency has applied the A.I. knowledge and other fields. Interconnectivity between other fields and A.I. has birthed various useful resolutions to the increased necessity of everyday outlooks. The motor-vehicle industry has employed a subset of A.I. to design self-driving and parking vehicles. The mechanism employed involves sensing the space outside the vehicle scheduled to be driven and packed in a particular signified place. The machines, therefore, have applied and mimicked the human processes to think and learn to meet several necessities and requirements out of circumstances. Opinionated views show fewer accidents shall be cut down because of the decreased number of physical driving availability. Self-driven vehicles have met such breakthroughs in companies such as Toyota, Mercedes-Benz, Audi, Volvo, and Telsa. The revolutionary of self-driven vehicles now leaves an impulsive motif in most people's innovation across the globe. For this reason, most innovations have been attributed to the advancement of A.I. in application to different fields and human lives. A close correlation has been enhanced between artificial intelligence and machine learning to incorporate innovation. Human experts have facilitated machine learning to computers in training to learn from its data feeds irrespective of explicit programming in every nature. Machine learning has facilitated artificial intelligence to be achieved in machines. 


\section{Research Methodology}

Qualitative methodologies and surveys were used to develop the hypothetical view of the impacts of A.I. on innovation across different institutions and social sectors in the world's economies. Interviews and focus groups were also incorporated in obtaining useful information on the impacts that are being experienced in all the fields of innovation through A.I. technologies. Several surveys on the facilities in the health sectors and interviews with the health workers also served to obtain the data that concerned advances in the technologies of health facilities and their diagnosis processes of different diseases (Donepudi, 2017b). Surveys in the industrial field of innovative application of A.I. technologies formed the core-basis of the research. The simulation method was also incorporated in the research to deduce and induce particular gaps in different fields. Social structures of the society were incorporated into the research on the complete views of how the people in the society viewed the innovations related to artificial intelligence application and their reliability.

\section{CAse ExAmple}

The installation of pedestrian crossing lights by Vienna Company has used A.I. concepts. The lights can recognize whenever pedestrians want to cross the road. It has replaced the traditional push button. It is advantageous to give a considerate time for large groups of people and people with disabilities to cross safely. The cameras have large visual fields and are equipped with a system that monitors and reports frauds via linked computers at the scene's immediate occurrence. They are compatible with all weather conditions. It will reduce many reported accidents on highways, and further; it aims to ensure reduced congestion and increased smoothness in traffic flow.

\section{SUMMARY OF INNOVATION TYPES}

\begin{tabular}{|l|l|}
\hline Sustaining Innovation & Disruptive Innovation \\
\hline Aims to satisfy customers' present needs & Satisfies customers' needs at a future date \\
\hline $\begin{array}{l}\text { Product performance is improved based on } \\
\text { the customers' feedback }\end{array}$ & $\begin{array}{l}\text { Performances are lowered by key featured } \\
\text { valued in the market }\end{array}$ \\
\hline $\begin{array}{l}\text { Aims at cutting down the defects and faster } \\
\text { improvement of products and more } \\
\text { powerful in operation }\end{array}$ & $\begin{array}{l}\text { There are many defects and less speed and } \\
\text { power of operation }\end{array}$ \\
\hline $\begin{array}{l}\text { Can lead to failure of the company because } \\
\text { it is effective in a short time }\end{array}$ & $\begin{array}{l}\text { The future of the company is guaranteed } \\
\text { from unproven opportunity due to } \\
\text { dedicating valuable resources to a niche }\end{array}$ \\
\hline
\end{tabular}

\section{POLICY IMPLICATIONS}

A.I. machines' approach to human intelligence and matching humans in particular tasks has promoted several innovative human history ideas. Technological advancement has been a notch in the application of artificial intelligence. The application of machine intelligence guides nearly every activity in the current modern life led by a man. It has fueled transformation in most industries, from small scale farming to robust filmmaking industries. More so, the more sophisticated A.I. becomes, the highly developed industries are enjoying its fruits.

\section{The Organization of Innovation and Management Policy}

Robots have been employed in the management of portfolios and hiring processes. Human Resource advisers have an extremely valued robotic approach to be efficient and reliable. 
Robotic use of A.I. has led to the development of a chatbot by a Russian startup, which is used to interview prospective employees. Besides, machine learning is being used in US-based Harver to cut down unconscious bias during the hiring process. Immune is not only being encompassed by medicine but is also greatly advanced by A.I. knowledge. Reports have shown that the A.I. application of knowledge has rapidly transformed the health industry. The pace at which A.I. has envisioned its functionality has superseded the health industries previously installed systems. A.I. advancement systems are better than radiologists. For this reason, A.I. has been structured to read mammograms to identify cancer lesions. Participation of every individual from varied fields and their interest in the visible potentiality of A.I. and machine learning great innovations have taken place across the globe.

Atomwise, a startup firm, is developing a novel technology that will be used to identify potential drug candidates using neural networks to predict candidate molecules' bioactivity. In the company's report, convolutional neural supersedes the performance of the conventional algorithm. According to Ayoade et al. (2017), training found from different data quantities shows that the company's Atom Net can mimic organic chemistry's basal structure and predict accurate outcomes of the actual physical experiments. And the result is the actual evidence of improvement in manufacturing and drug screening. Atomwise technology and other companies are still at the earliest stage of innovation in A.I. to discover more drugs in the health sectors and diagnose diseases.

Further, discoveries in Atomwise technology are designing the development of pesticides and crop disease control. A.I. is directly illustrated by Atomwise technologies with the potential to impact innovation. Even though artificial intelligence is the route to computer science, it is commercially used in narrow fields such as robots. Robotics is the learning algorithm continually growing and proving that A.I. applications will dominate a broader field of human existence. Robotics will serve the purpose of small tasks, especially in developing neural networks and machine learning. A.I., to some extent, is the extensional efficiency of the previous methods of performing tasks. For this reason, some innovations are being unleashed to the accustomed approaches to the traditional or the outpaced means of undertaking the general tasks.

\section{Economic Cost}

The application of A.I. machines has promoted lower-cost and high-quality inputs in innovative, productive processes. As a result, large job displacement lies in the risk of being spurred. On the other hand, machine learning prospects to increase productivity and influence change in the whole process of innovation employing innovative domains. The Griliches (1957) is potentially intended to induce a greater economic impact on every product produced in the productive system. Recent advancement in machine learning and A.I. and neural networks to improve performance through technological use and nature of innovation is likely to impact the innovation pace and its growth in the entire industrial field. For this reason, the incentives and drawbacks that may accompany the whole process of these technologies and their exploitation form the thesis for economic research on innovation. Also, making out the conditions that will necessitate most innovators' operational activities and how they will gain access to the tools and use them in competitive lies in the eyespot of the whole projection of innovation.

\section{A.I. Innovation and the Future Competition Policy}

This paper begins to unveil the potential impacts of advances in A.I. on innovation and identifying different roles that policy and institutions presuppose to enact to ensure effective incentives for innovation, spreading, and competitive motifs that can be created in the field. Starting by highlighting the most key economic tools from which machine learning 
applied to R\&D situations gives a major key playing study case. The interplay between the degree of the general application of recent research tools and their functionality enhances efficiency. The creation of new drafted means for innovation itself is the second focus on the impacts that have resulted from innovation. Thirdly, a brief contrast of the three key technological advancements into the innovation field; the AI0- robots, deep machine learning, and symbolic systems will offer the expectation of impacts in the future. These three factors will act as major varied roles in the future hope of innovation and technological changes. Symbolic systems are seemingly to be of relatively less impact on innovation shortly because they appear to be stalled in the present times. Even though the robotic application in technologies carries a higher potentiality to displace human labor in the economic structure and production of several goods and services, innovation is hard to change by several innovations in the robotic technologies parse. Deep machine learning is an area of deeper research that carries a high probability of potentially serving the generapurpose and changing the innovation process and its approaches.

Conceptual thinking of A.I. has opened up the economic research tools and avenues of improved productivity and inquiry. They constitute new means of creating products with varied applications in the market. For this reason, some inventions of A.I. reduce the cost of particular intended innovation in different fields where the new domain is employed and put into application. Advancements in the invention of A.I. and neural networks possess a greater potentiality as a research tool in classification and prediction. Their applications have helped provide a solution to several drawbacks to most research tasks in machine learning; hence, the whole research process has become cost-effective and improved performance in the R \& D projects. The robotic concepts in the formulation of innovation have been greatly apprenticed to perform human tasks more effectively in the late 1980s (Donepudi, 2016). Advanced controlled machines have also been attributed to A.I. advances that rely on the natural environment's sensation. The robotics machines are attributed to the performance of duties because they are precisely and highly programmed. As a result, robots' innovations have resulted in notable efficacy and effectiveness in the manufacturing and automation industry. The process has been made possible by introducing A.I. in the responsive nature of robots conversant with programmed algorithms that respond appropriately to the surrounding external environment. The approach was pioneered by Brooks \& Storey (1990), and it focused on the innovation and commercial application of A.I. to mimic the human intelligence model and provide practical and effective robotics in different fields. Hence, much industrial robotics have been created that have fastened human labor in the industrial arena. The universal application of robotics technologies and innovations may result in flooding and wider application and adoption in other sectors of scientific applications.

\section{POSITIVE IMPLiCATIONS OF POLICING}

Most human life changes have either positive or negative influences on productive nature, as innovation continues to transform the world. Several debate contexts raise a matter of concern on achieving the balance between negative and positive impacts. However, the changes will be good and challenging for other people in society. The realm of dealing with them appropriately should utmost be treated in a beneficial and optimistic approach. There will be a dramatic improvement in human workplaces' efficiencies and arguments the type of work that suits human abilities and health requirements. Many dangers and risks have been wiped away and eliminated by A.I. in tasks that were initially obligated to human labor. A.I. has created room for specialization in machine operations as a way of integrating job performances. Human beings control some of the robotic technologies, and it is indirect 
duty performance without physical involvement. A.I. has created creativity and empathy in promoting innovation in most working populations; hence, the result has led to increased satisfaction at the workplace. Healthcare has been dramatically influenced through innovations via A.I. Better monitoring, and diagnostic abilities of A.I. have improved healthcare facilities and medical organizations' operations. Less cost has been incurred since the application of A.I. technologies has taken part in the healthcare process. McKinsey estimates that that big data could save healthcare operations up to $\$ 100 \mathrm{~B}$ annually, which reciprocates to the true care of the patients who will benefit from the innovative means and measures of the A.I. technologies. Protocols on drugs and personalized treatments will also be easily accessed in clearer informational technology and change lives. A.I. technologies applications in working robotics will help society to gain an increased hour of productivity. Also, the introduction of autonomous transportation and traffic congestion eradication will free humans from time-consuming activities (Masud-Ul-Hasan et al., 2015). Detection of criminal and terrorist acts will also be put under human monitoring and control in the society via innovation of facial recognition technology created through the knowledge of A.I. Judicial systems also have employed A.I. in safeguarding individuals' privacy.

\section{NEGATIVE IMPLICATIONS OF POLICING}

On the negative side, society is going to experience evolvement in the workforce of its people. The threat virally presupposes that human beings are going to lose jobs to the machines. Society, therefore, needs to adapt to the accelerative thrust to have passionate minds in the responsibilities that entail their mimicked human abilities. A.I. will replace seven million existing jobs in the U.K. from 2017 to 2037. Also, 7.2 million jobs shall be created within the period; however, adopting the new system to the manner of making a living will pose a challenge to most of the population. The transformative actions of innovations birthed by A.I (Donepudi, 2016), in the society shall impose the political, economic, and legal implications that bases foundations for serious discussions in preparation of the faults that might cause different implications for both lives and the sustainable human environment (Taher-UzZaman et al., 2014). For instance, autonomous vehicles' innovation should be taken into consideration of who will be at fault whenever flaws in their operation and mischievous loss of lives when pedestrians are hurt. For this reason, global autonomous arms race examples of weakness in the operation of autonomous vehicles. Furthermore, unintended A.I. outcomes such as machine becoming super-intelligent will pose a great risk to all human beings. The consequences may be vast beyond the creators of such A.I. machines. The algorithms used in the A.I. formulations are supposed to align with the varying goals of human culture. Otherwise, if the duty performed by A.I. machines will take proficiency in tasks performed by human beings, then conflicts will arise in the negative direction of the economic society (Donepudi, 2017a). A.I. innovations will negatively devolve into social oppression in society. Why? The reliance on A.I. algorithms on data-powered technology from every individual's daily activity at close intervals will alter society's privacy. For instance, if every government and business will take the route of China's social credit system, to make decisions based on the A.I. machine intelligence, society's social system will experience a depression gap.

\section{ANALYSIS}

Society today is accustomed to clinking to whatever makes them realize their goals in a short time and effective means. The more effective the positive impacts add value to many lives and sector in the society, the more profound the idea and projection of the innovation finds vast applications. For this reason, the methodology used to collect the data in the research to 
illustrate the impacts of A.I. on innovation unveiled some analysis. Most of the services associated with the innovative approach of A.I. were highly preferred than other means. Most interviewees responded positively about the application of robotics knowledge in industrial applications. Robotics increased production periods than expected from a man if they had to carry out the same duties and tasks. Most health sectors appreciated the employment of A.I. knowledge in the diagnosis of diseases. Specifically, immune diseases were effectively diagnosed by new innovative apparatus which employed A.I. mimicry technologies. Most surveys revealed that patient treatment had achieved higher levels in the general health sectors, unlike the existing technology's past experiences. However, some pros and cons accompanied the impacts of A.I. on innovations. Respondents revealed that A.I. would birth means of production in society that would lead to conflicts between humans' duties. In this case, disruptive innovations disputed general inventions and development in society (Rahman et al., 2013). Also, most interviewees presented the worries of replacement in the jobs which are rendered to be performed by humans (Donepudi, 2016). However, experts advised that humans need to adjust and fit in the new duties of operating such machine learning to avoid being outpaced by the innovations checked by A.I.

\section{RECOMMENDATIONS}

The qualitative research results provide some of the first-hand information on A.I.'s impacts on innovation worldwide and their applications at a significantly accelerating pace. The research got information from varied groups of academic, government, and industrial researchers. The survey research method showed full evidence of the respondents' full perception in health, social, and industrial sectors perceive the impacts and the positive and negative outcomes of A.I. innovations. The means of collecting the researched data aimed at increasing A.I.'s versatility and its innovation in the community while trying to put some measures to reduce the limitations that can be obsessed with society. Even though survey methodology is useful in research, the results should view insights due to low response rates and possible bias responses. The dilemmas by researchers arising from the survey have found different interpretations of responses in varied ways. Other methods, such as questionnaires, should be employed in this research to further far-reach most populations. Generally, survey research shows that most of the populations have appreciated the positive innovations of A.I. applications in technologies. The research further suggests that employing different models to serve as a deeper scope in different fields and the social society of humans, and the appropriate action that can be taken to combat the negative impacts that may result from A.I. inventions and innovations.

\section{Model ReCOMmendations}

Models are designed to provide suggested solutions to coherent problems and the scope of the research. The three-dimensional model will be effective and in the evaluation of accuracy. The model assumes a considerable amount of time enough to conduct the research. Field experience is the necessity to obtain information in this study. It enhances understanding of the background practices in the innovation and technological field. Besides, clear and strong communication, technological innovations, and technological knowledge background are the background cues to carry out the research.

\section{CONCLUSION}

Human beings have no choice to positively interact with modern technology unless they prefer to stagger in the remote world. Their lives are significantly gradually continuing to be impacted by artificial intelligence. As far as more changes and challenges will be 
continuously be encountered throughout the development process, the resultant impacts are opted to be positive and less negative on the worst scenarios in our societies across the globe. The purpose of this explorative research has been to illustrate the impacts which have been realized in various innovations due to A.I. Also, deep machine learning has been explored with the possibility of presenting a general application of invention preliminary policies in institutions, policy, and management. Most inventions have been linked to economic growth in society. A.I. innovations have invented new methods of approaching certain tasks in society. The industrial and healthcare sector have also experienced robust benefits and implications of innovations that have resulted from the general and complex application of A.I. in the operation and running of different activities. Innovation perspective has helped human beings to differentiate between vital and important advancements in robotics and the neural networks, and large data sets due to A.I. application in different fields. The implicative changes in the related prospects of key policies and management ranging from the evaluation to prediction of potential ways induce new barriers across every field in the application of A.I. Analysis from both sectors ranging from socio-economic to the massive industrial application provides a promising future vast flooding of A.I. knowledge and technologies in most sectors in the society.

\section{REFERENCES}

Ayoade, A. A., Salako, S. G., Yusuf-Babatunde, A. M., Lawal, O. A., \& KuKu, M. A. (2017). Assessment of Perceived Health and Environmental Problems of Household Energy Consumption among Ilese Ijebu Residents Southwestern Nigeria. Asia Pacific Journal of Energy and Environment, 4(2), 41-48. https://doi.org/10.18034/apjee.v4i2.241

Brooks, S. P. J., \& Storey, K. B. (1990). Where is the glycolytic complex? A critical evaluation of present data from muscle tissue. FEBS letters, 278(2), 135-138. https://www.sciencedirect.com/science/article/pii/0014579391801018

Donepudi, P. K. (2016). Influence of Cloud Computing in Business: Are They Robust? Asian Journal of Applied Science and Engineering, 5(3), 193-196. http://doi.org/10.5281/zenodo.4110309

Donepudi, P. K. (2017a). AI and Machine Learning in Banking: A Systematic Literature Review. Asian Journal of Applied Science and Engineering, 6(3), 157-162. http://doi.org/10.5281/zenodo.4109672

Donepudi, P. K. (2017b). Machine Learning and Artificial Intelligence in Banking. Engineering International, 5(2), 83-86. https://doi.org/10.18034/ei.v5i2.490

Griliches, Z. (1957). Hybrid corn: An exploration in the economics of technological change. Econometrica, Journal of the Econometric Society, 501-522. https://www.jstor.org/stable/1905380

Happy, F. A., Hossain, M. S., \& Rahman, A. (2015). Pressure Data Analysis and Multilayer Modeling of a Gas-Condansate Reservoir. Asia Pacific Journal of Energy and Environment, 2(1), 7-16. https://doi.org/10.18034/apjee.v2i1.219

Masud-Ul-Hasan, M., Rahman, M. H., \& Rana, M. (2015). Identifying Service Quality Attributes and Measuring Customer Satisfaction of Dhaka-Pabna Route Public Bus Service. Asian Business Review, 5(2), 72-78. https://doi.org/10.18034/abr.v5i2.57

Rahman, M. H., Kamruzzaman, M., Haque, M. E., Mamun, M. A. A., \& Molla, M. I. (2013). Perceived Intensity of Stress Stressors: A Study on Commercial Bank in Bangladesh. Asian Business Review, 3(1), 40-43. https://doi.org/10.18034/abr.v3i1.101

Taher-Uz-Zaman, M., Ahmed, M. S., Hossain, S., Hossain, S., \& Jamal, G. R. A. (2014). Multipurpose Tactical Robot. Engineering International, 2(1), 21-27. https://doi.org/10.18034/ei.v2i1.204

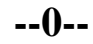

